\title{
SPECTRUM OF SUDDEN CARDIAC DEATH IN NEPALESE POPULATION - AN INSTITUTIONAL BASED STUDY -
}

\author{
Chaudhary $\mathrm{A}^{1}$, Kadel T${ }^{2}$, Wasti $\mathrm{H}^{2}$ \& Shrestha PK ${ }^{2}$
}

DOI :

http://doi.org/10.4038/sljfmsl. v11i2.7813

Corresponding Author Chaudhary A

1 Kathmandu Medical College, Kathmandu, Nepal

archiechaudhary@yahoo.com (iD https://orcid.org/ 00000003-0709-986X

2 Department of Forensic Medicine, Institute of Medicine, Kathmandu, Nepal

\section{Key Words}

Cardiac tamponade;

cardiomyopathy; coronary artery disease; sudden and unexpected death; sudden cardiac death

Article History

Received: 31.05.2020

Received in revised form: 20.07.2020

Accepted: 26.08 .2020

Available online: 21.12 .2020

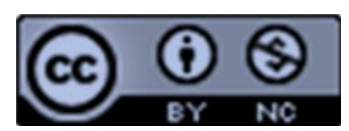

This article is licensed under the terms of the Creative Commons Attribution-Non Commercial 4.0 International License.

e-ISSN: 2465-6089

\section{ABSTRACT}

Introduction: Sudden cardiac death (SCD) is non traumatic deaths occurring within 24 hours from the onset of symptom due to a cardiac cause. This study was designed with an objective to evaluate spectrum of SCD in the Nepalese community.

Materials and Methods: This was a prospective analytical study, done at an autopsy center in Nepal, over one year. All SCD's were verified using histopathological examination. Analysis was done using SPSS, Version-20. Mean and standard deviation was calculated for age. The frequency and percentage were calculated for gender, and cause of death. Stratification was done for age and post-stratification Chi square test or Fisher exact test was used.

Results: There was a total of 51 cases, with $44(86.3 \%)$ males and $7(13.7 \%)$ females. Peak death was between $40-60$ years. The most common cause of death was coronary artery diseases (CAD) (62.7\%). There was significant association of gender with the different spectrum of SCD, with male gender having tendencies towards CAD and cardiomyopathy (CM).

Conclusion: Coronary artery disease is the commonest cause of sudden cardiac deaths, followed by cardiomyopathy. Both these diseases had significantly increased tendencies towards male gender.

\section{INTRODUCTION}

Sudden and unexpected natural death is defined as death that is non-violent and not otherwise explained, occurring within 24 hours from the onset of symptom. ${ }^{1}$ The most common cause of sudden death is cardiovascular diseases and coronary artery disease is responsible in almost $80 \%$ of cases. ${ }^{2}$

Cardiomyopathies (CM) are characterized by myocardial dysfunction and are further categorized into dilated or congestive, hypertrophic, and restrictive-obliterative. ${ }^{2}$ The most common is congestive or dilated cardiomyopathy which is characterized by enlargement, sometimes massive, with dilatation of all four chambers. ${ }^{2}$

Valvular disease attributable to sudden cardiac death (SCD) usually involves either mitral valve prolapse or aortic stenosis, which is present in $5-15 \%$ of the population. ${ }^{2}$

Aortic dissection occurs when blood dissects between the middle and outer two thirds of the aortic media, creating a blood-filled channel within the aortic wall. ${ }^{3}$ Genetic abnormalities, weight-lifting and cocaine abuse have been associated with aortic dissection. ${ }^{4,5}$

Since, there may be racial and geographical variations, this study was designed with the objective of determining the pattern and frequency of sudden cardiac deaths (SCD) in an autopsy center in Nepal. 


\section{MATERIALS AND METHODS}

This is a prospective analytical study performed at Department of Forensic Medicine, Maharajgunj Medical Campus, Institute of Medicine, Tribhuvan University, Kathmandu, Nepal. This study was performed over the duration of one year, where, a non probability, purposive sampling technique was used. All the cases of sudden and unexpected death of Nepalese citizens brought to the department of Forensic Medicine which was diagnosed to be of cardiac origin was included in this study. Deaths due to trauma, suicide or homicide and all cases of advanced decomposition semiskeletonized and skeletonized remains were excluded from this study.
All the cases of sudden and unexpected deaths brought to the center underwent medico-legal autopsies and cardiac causes were verified using histopathological analysis in all cases. This information including name, age, and gender were entered into the study proforma. Analysis was done with software SPSS, Version 20. The mean and standard deviation was calculated for age. The frequency and percentage were calculated for gender, and cause of death. The effect modifier like age and gender were controlled through stratification to see the effect of these modifiers on the outcome. Poststratification Chi square test or Fisher exact test were used where applicable.

\section{RESULTS}

There was a total of 51 cases of SCD. Forty-four (86.3\%) were male. The peak age of death was $40-60$ years, with a mean age of 46.59 years $(S D=16.288)$ (Fig. 1$)$.

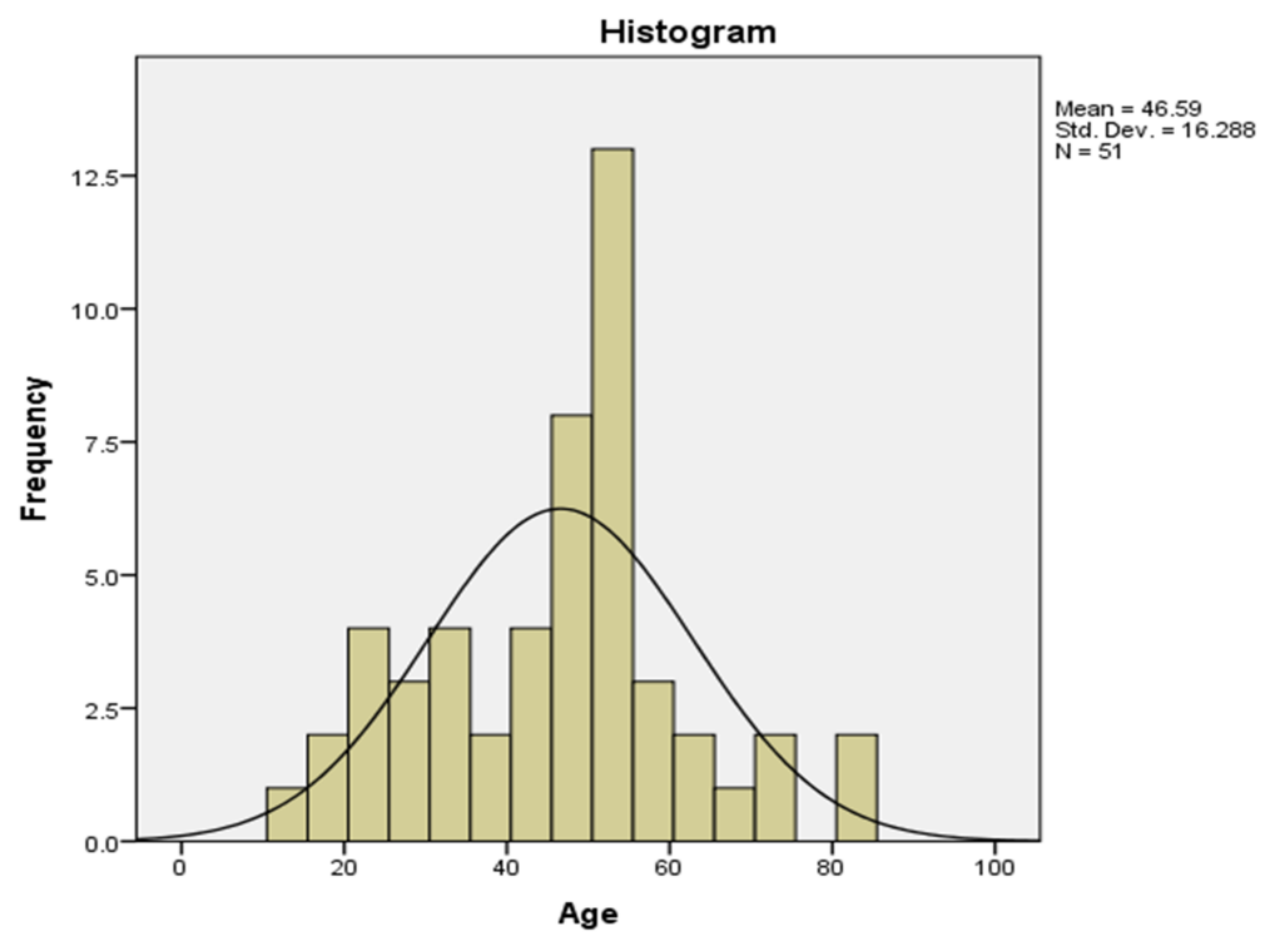

Fig. 1: Age distribution of the sudden cardiac deaths

The most common cause of death was coronary artery disease (CAD) which was $62.7 \%$ of all the sudden and unexpected cardiac deaths (Table 1). These deaths were more common at 50-59 years of age. However, these findings were not statistically significant among the different causes of sudden cardiac deaths (Table 2). On the other hand, there was a significant association between gender and the different spectrum of $\mathrm{SCD}$, with male gender having tendencies towards $C A D$ (93.75\%, 30/32) and CM (100\%, 8/8) (Table 3). 
Table 1: Spectrum of different causes of sudden and unexpected cardiac deaths

\begin{tabular}{ll}
\hline Cause of death & Number of cases \\
\hline Coronary artery disease (CAD) & $32(62.7 \%)$ \\
\hline Cardiomyopathy (CM) & $8(15.7 \%)$ \\
Aortic dissection (AD) & $5(9.8 \%)$ \\
Valvular heart disease (VHD) & $3(5.9 \%)$ \\
Dissecting coronary artery & $1(2 \%)$ \\
Myocardial rupture without CAD & $1(2 \%)$ \\
Ventricular aneurysm & $1(2 \%)$ \\
\hline
\end{tabular}

Table 2: Relation of age with the different cardiac causes of deaths

\begin{tabular}{lllllllll}
\hline $\begin{array}{l}\text { Age } \\
\text { Category }\end{array}$ & AD & CAD & CM & $\begin{array}{l}\text { Dissecting } \\
\text { coronary } \\
\text { artery }\end{array}$ & $\begin{array}{l}\text { Myocardial } \\
\text { rupture } \\
\text { without CAD }\end{array}$ & $\begin{array}{l}\text { Ventricular } \\
\text { aneurysm }\end{array}$ & VHD & P value \\
\hline $\mathbf{1 0 - 1 9}$ & 0 & 1 & 0 & 0 & 1 & 0 & 1 & 0.36 \\
\hline $\mathbf{2 0 - 2 9}$ & 2 & 2 & 2 & 0 & 0 & 0 & 1 & \\
$\mathbf{3 0 - 3 9}$ & 0 & 3 & 1 & 0 & 0 & 0 & 0 & \\
$\mathbf{4 0 - 4 9}$ & 2 & 6 & 2 & 1 & 0 & 0 & 0 & \\
$\mathbf{5 0 - 5 9}$ & 1 & 13 & 3 & 0 & 0 & 1 & 0 & \\
$\mathbf{6 0 - 6 9}$ & 0 & 4 & 0 & 0 & 0 & 0 & 0 & \\
$\mathbf{7 0 - 7 9}$ & 0 & 2 & 0 & 0 & 0 & 0 & 0 & \\
$\mathbf{8 0 - 8 9}$ & 0 & 1 & 0 & 0 & 0 & 0 & 1 & \\
\hline Total & 5 & 32 & 8 & 1 & 1 & 1 & 3 & \\
\hline
\end{tabular}

AD: Aortic Dissection, CAD: Coronary Artery Disease, CM: Cardiomyopathy, VHD: Valvular Heart Disease

Table 3: Relation of gender with the different cardiac causes of deaths

\begin{tabular}{llllllllll}
\hline Gender & AD & CAD & CM & $\begin{array}{c}\text { Dissecting } \\
\text { coronary } \\
\text { artery }\end{array}$ & $\begin{array}{c}\text { Myocardial } \\
\text { rupture without } \\
\text { CAD }\end{array}$ & $\begin{array}{c}\text { Ventricular } \\
\text { aneurysm }\end{array}$ & VHD & P value \\
\hline Female & 2 & 2 & 0 & 1 & 1 & 0 & 1 & $0.008^{*}$ \\
Male & 3 & 30 & 8 & 0 & 0 & 1 & 2 & \\
Total & 5 & 32 & 8 & 1 & 1 & 1 & 3 & \\
\hline
\end{tabular}

AD: Aortic Dissection, CAD: Coronary Artery Disease, CM: Cardiomyopathy, VHD: Valvular Heart Disease 


\section{CORONARY ARTERY DISEASE}

\section{Single vessel involvement}

More than $75 \%$ of the lumen of left anterior descending coronary artery (LAD) was stenosed in 20 cases. Among these, six showed features of acute myocardial infarction in histopathological examination, one had developed cardiac tamponade following posterior lateral ventricle rupture at due to acute myocardial infarction, one showed features of old myocardial infarction and three showed features of both acute as well as old myocardial infarction. The other nine cases did not show any cardiac changes on histopathological examination.

There were four cases of right coronary artery (RCA) involvement. Among them, one case was stenosis with only pinpoint opening of lumen (more than $90 \%$ blocked) at the level of origin of RCA, and three cases were associated with thrombosis in RCA with more than $75 \%$ stenosis. Two out of these three cases had features of acute myocardial infarction on histopathological examination.

\section{Two-vessel involvement}

Two vessel involvement was seen in four cases. More than $75 \%$ of lumen of LAD and RCA were stenosed in two cases, of which, one case showed features of old myocardial infarction. More than $75 \%$ of lumen of LAD and Circumflex artery was stenosed in one case. More than $75 \%$ of lumen of RCA and circumflex was stenosed in one case and showed features of old, as well as acute, myocardial infarction.

\section{Triple vessel involvement}

There were four cases of triple-vessel involvement with over $75 \%$ of luminal stenosis. Among the cases of triple-vessel disease, one had left postero-lateral ventricular wall rupture following $\mathrm{AMI}$, one had only stenosis and the other two had both features of AMI and old MI.

\section{Cardiomyopathy (CM)}

There were eight cases of deaths due to $\mathrm{CM}$, four had dilated CM (Fig. 2) and four had hypertrophic CM (Fig. 3). One of the four cases of dilated CM was alcoholic CM. Three cases of hypertrophic CM were associated with LAD bridging.

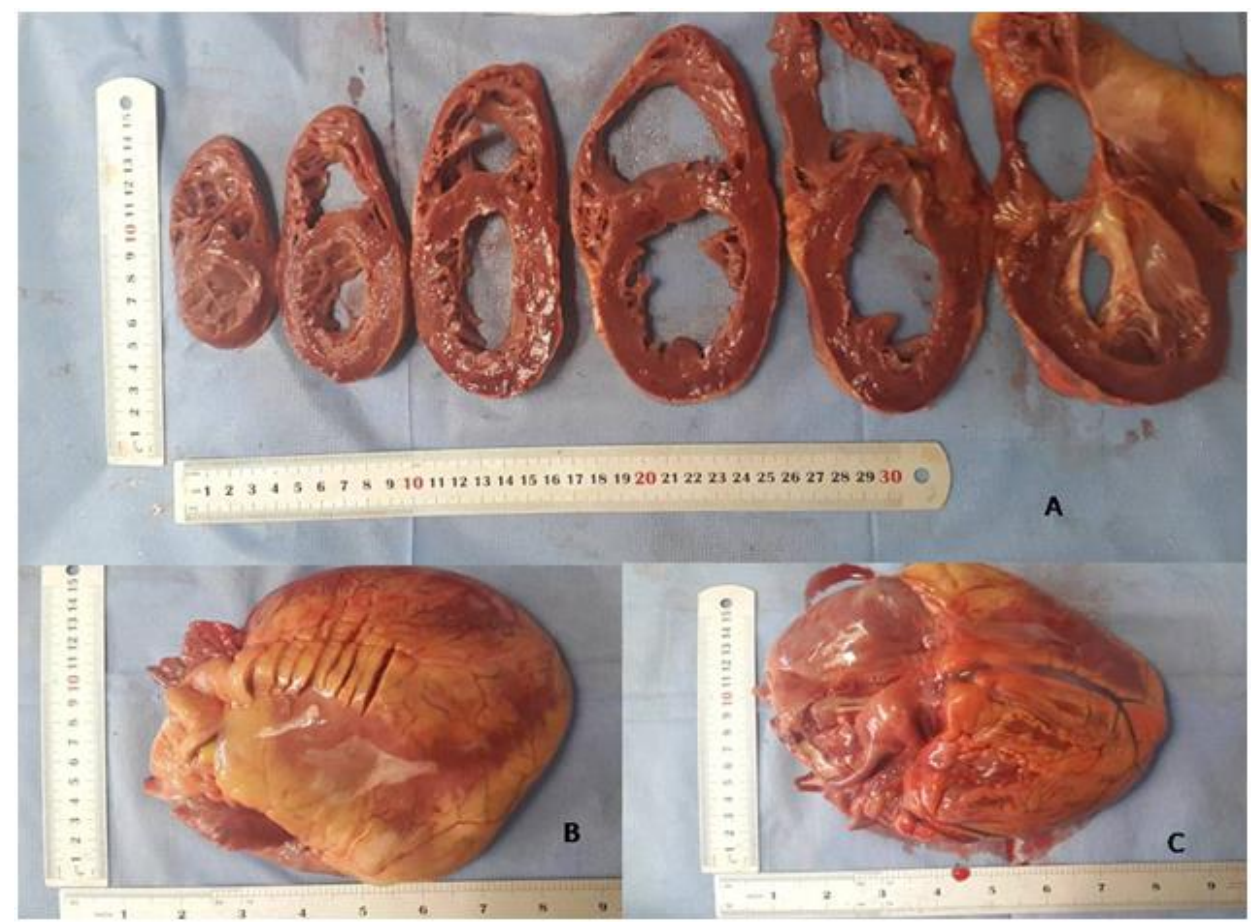

Fig. 2: Dilated cardiomyopathy, shown in cross section (A), anterior view (B), and posterior view (C) 


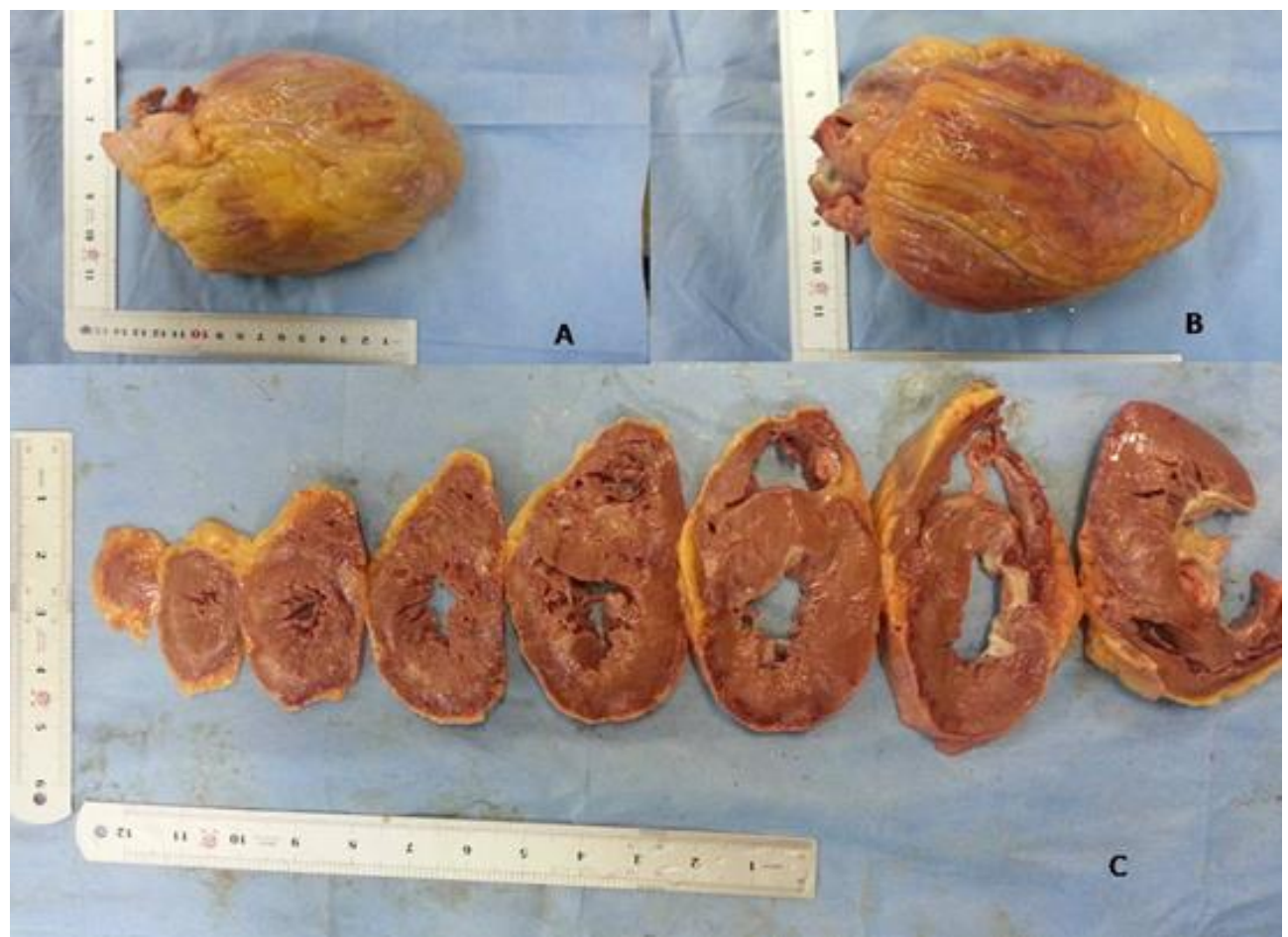

Fig. 3: Hypertrophic cardiomyopathy, shown in anterior view (A), posterior view (B), and cross-section (C).

\section{Aortic dissection (AD)}

There were five cases of $A D$ with dissection at the level of the ascending aorta (Fig. 4). Four of these cases were associated with cardiac tamponade and one had only intimal dissection occluding only the arterial lumen.

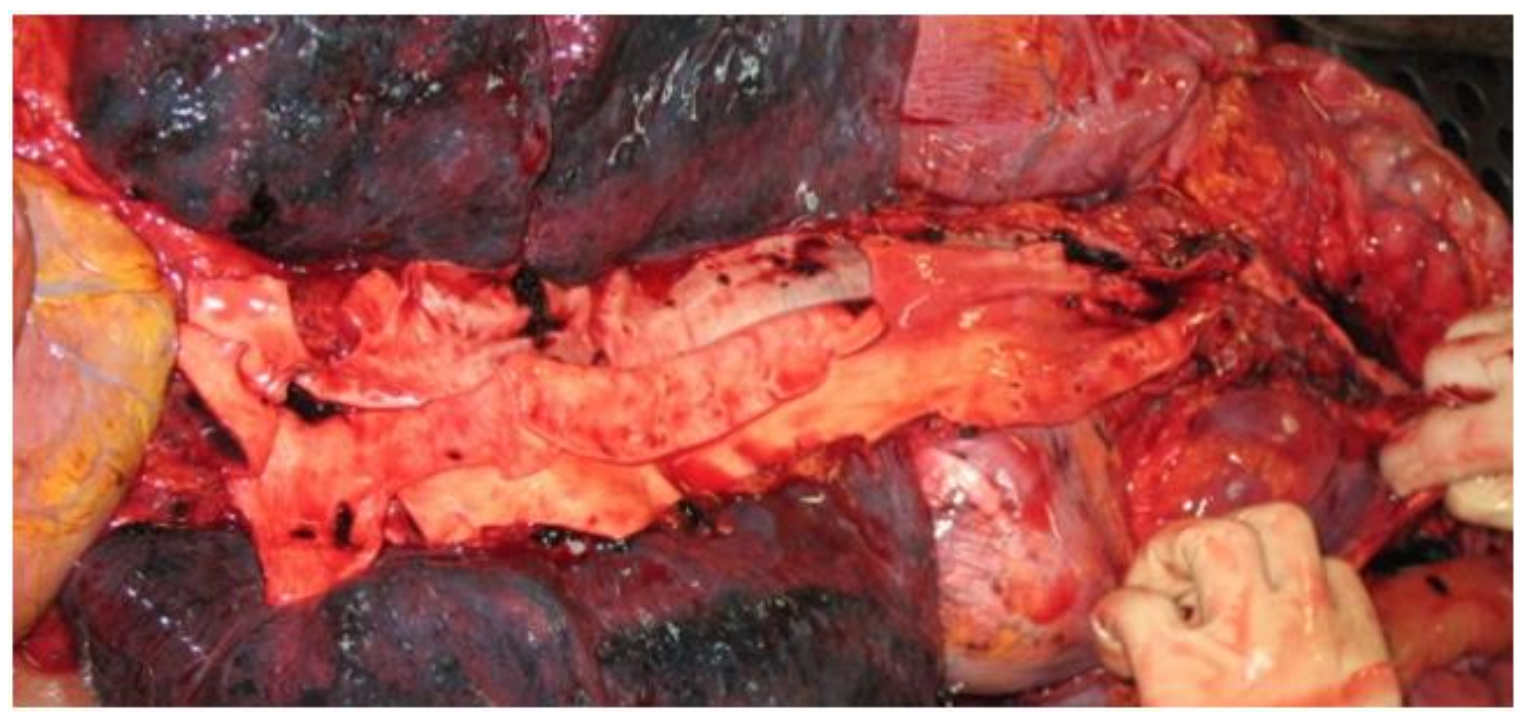

Fig. 4: Aortic dissection starting from the ascending aorta 


\section{Valvular heart disease (VHD)}

There were three deaths due to VHD. One was due to rheumatic heart disease, the second had mitral stenosis with calcified aortic and mitral valves, and the third had aortic stenosis due to primary degenerative calcification.

\section{Dissecting coronary artery}

There was one case of a dissecting right coronary artery associated with a cardiac tamponade.

\section{Myocardial rupture without CAD}

There were three cases of myocardial rupture where two were ventricular ruptures associated with CAD. However, there was one case of isolated myocardial rupture without CAD, where there was right atrial rupture with cardiac tamponade. This was a 16-year-old syndromic boy with cerebral palsy; however, the exact underlying cause of rupture was unknown.

\section{Ventricular aneurysm}

Only one case of ventricular aneurysm was seen which was associated with ventricular scarring at the aneurysm site.

\section{DISCUSSION}

Literature revealed that cardiovascular disease is the most common cause of sudden and unexpected natural deaths. ${ }^{6,7}$ This study revealed that CAD accounts for the highest number of deaths $(62.7 \%)$. This finding is similar to the findings of Zipes and Wellens where up to $80 \%$ of the individuals dying suddenly of cardiac disease died of coronary artery disease. $^{6}$

\section{Coronary artery disease}

SCD as a result of a single coronary vessel disease was confined to only $11.9 \%$ in the study of Di Maio et al where 451 deaths due to CAD were analyzed. ${ }^{7}$ However, in this study 75 $\%$ (24 out of 32 cases) had a single vessel involvement, which is significantly higher than that seen in the Di Maio study. This variation may be attributed to the difference in the nature of the population studied. Among the deaths with a single vessel involvement in our series, $83 \%(20 / 24)$ were due to the involvement of the LAD (Fig. 2), and this vessel seems to be the main affected artery in other autopsy series as well. ${ }^{7}$

The involvement of two and three vessels among the cases of coronary artery diseases in this study which was only about $25 \%$, was similar to the findings by DiMaio \& Di Maio. ${ }^{7}$ De Wood et al in their series had $34.8 \%$ of the deaths attributed to an old infraction and myocardial scarring, and only $8.4 \%$ of the deaths had evidence of $A M I$ associated with CAD. ${ }^{8}$ In this study, among the 32 cases of CAD, $62.5 \%$ of the deaths had either an old MI (12.5 $\%)$, or AMI (37.5\%), or both (12.5\%.).

Occasionally, other anatomical variations may be seen in the vessels besides coronary atherosclerosis. The death of one case in our series was attributed to a pinpoint opening of the right coronary artery. Similarly, coronary artery disease may have complications such as cardiac rupture leading to cardiac tamponade, which was observed in two case of CAD due to single vessel and triple vessel disease.

\section{Cardiomyopathy}

This is associated with myocardial dysfunction of unknown etiology, and is not related to arteriosclerotic, hypertensive, congenital, or valvular disease. ${ }^{2}$ In our study, we observed that cardiomyopathy accounted for $15.6 \%$ of deaths due to cardiovascular causes, where $50 \%$ was due to dilated and $50 \%$ due to hypertrophic cardiomyopathy. Cutler \& Wallace had $30-50 \%$ of hypertrophic cardiomyopathy deaths in their series associated with bridging of the coronary artery, most commonly the left anterior descending. Sudden death due to this phenomenon was also stressed by Morales et al. ${ }^{9,10}$

In this study, there were three LAD bridging out of four cases of hypertrophic CM. 
We had no cases of restrictive-obliterative CM in this study, and it has been noticed that this category of $\mathrm{CM}$ rarely causes sudden and unexpected death and is usually associated with other chronic diseases like amyloidosis, haemochromatosis, sarcoidosis, glycogen storage disease, and hypereosinophilic syndrome.

\section{Aortic dissection (AD)}

Pathologically, in $A D$, there is blood dissecting between the middle and outer two thirds of the aortic media, which forms a blood-filled channel in the aortic media. ${ }^{3}$ This is more common in the ascending aorta and this dissection can rupture into the lumen of the aorta or into the pericardial sac. ${ }^{3,7}$ In this study, $9.8 \%$ of deaths due to cardiovascular causes were due to this pathology and all of them were at the level of ascending aorta. Davies et al. also report that this is overwhelmingly the most common site. Our series had $80 \%$ of the aortic dissections, associated with cardiac tamponade. $^{3}$

\section{Valvular heart disease, dissecting coronary artery, myocardial rupture without CAD, and ventricular aneurysm}

The exact proportion of deaths due to valvular heart diseases was difficult to extract from the literature, although valvular heart disease is quoted as one of the common causes of deaths due to cardiovascular causes. ${ }^{11}$ The most common cause of sudden death as a result of valvular heart disease seems to be mitral valve prolapse followed by aortic stenosis and acute bacterial valvulitis as per Selzer. ${ }^{11}$ However, in this study there were only three cases of sudden and unexpected deaths due to valvular heart disease, and thus not a common cardiovascular cause of death in our series.

A few rare cases of sudden and unexpected deaths due to cardiovascular causes were also encountered in this study; dissecting coronary artery, myocardial rupture (two associated with coronary artery disease and one not associated with coronary artery disease), and a case of ventricular aneurysm.

\section{CONCLUSION}

Coronary artery disease is the commonest cause of sudden cardiac deaths, followed by cardiomyopathy. Both these diseases were significantly higher in males.

\section{ETHICAL ISSUES}

None

\section{CONFLICTS OF INTEREST}

There are no conflicts of interest.

\section{AUTHOR CONTRIBUTIONS}

AC: Data collection and report writing;

TK: Data analysis;

HW: Critical revision and final approval;

PKS: Concept and design of work

\section{REFERENCES}

1. World Health Organization. International Statistical Classification of Diseases and Related Health Problems - 10th revision, edition 2010. III-defined and unknown causes of mortality. 10th ed. WHO; 2011.

2. Wynne J, Braunwald E. The cardiomyopathies and myocarditis: toxic chemical and physical damage to the heart. In: Braunwald E. (eds.). Heart Disease. 4th ed. Philadelphia: WB Saunders; 1992.

3. Davies MJ, Treasure T, Richardson PD. The pathogenesis of spontaneous arterial dissection. Heart. 1996 May;75(5):434. doi:10.1136/ hrt.75.5.434

4. Fikar CR, Koch S. Etiologic factors of acute aortic dissection in children and younrg adults. Clinical pediatrics. 2000 Feb;39(2):71-80. doi: $10.1177 / 000992280003900201$

5. Rashid J, Eisenberg MJ, Topol EJ. Cocaineinduced aortic dissection. The American heart journal. 1996;132(6):1301-4.

6. Zipes DP, Wellens HJ. Sudden cardiac death. Circulation. 1998;98(98):233451. 
7. Di Maio VJM, Di Maio DJM. Incidence of coronary thrombosis in sudden death due to coronary artery disease. The American journal of forensic medicine and pathology. 1993 Dec;14(4):273-5. doi:10.1097/ 00000433199312000-00001

8. DeWood MA, Spores J, Notske R, Mouser LT, Burroughs R, Golden MS, Lang HT. Prevalence of total coronary occlusion during the early hours of transmural myocardial infarction. New England Journal of Medicine. 1980 Oct 16;303(16):897-902. doi:10.1056/NEJM198010163031601
9. Morales AR, Romanelli RE, Boucek RJ. The mural left anterior descending coronary artery, strenuous exercise and sudden death. Circulation. $\quad 1980 \quad$ Aug;62(2):230-7. doi:10.1161/01.CIR.62.2.230

10. Cutler D, Wallace JM. Myocardial bridging in a young patient with sudden death. Clinical cardiology. $1997 \quad$ Jun;20(6):581-3. doi:10.1002/clc.4960200614

11. Selzer A. Changing aspects of the natural history of valvular aortic stenosis. New England Journal of Medicine. 1987 Jul 9;317(2):91-8. doi:10.1056/NEJM198707093170206 